\title{
CONCEITO DO CORRETO E DO INCORRETO NA LINGUAGEM
}

\section{CRITÉRIOS $(*)$}

\author{
R. F. MANSUR GUÉRIOS \\ (Universidade Federal do Paraná)
}

Trata da correção da linguagem, das questões do que se deve ou não se deve dizer, não só a escola, mas ainda e principalmente os gramáticos e puristas, e, não poucas vêzes, através da imprensa, essas questões passam a ser discutidas com ênfase, com entusiasmo, e o que é de admirar, têm a simpatia do público em geral, principalmente no Brasil.

Certas revistas de Filologia, principalmente as de outrora, reservavam uma seç̧ão para atender a consultas (1).

- Mas qual é o critério da certeza na linguagem?

O problema é complexo, e os lingüistas, que são os mais competentes para discuti-lo, em geral não the dão atenção; preferem outros problemas, muitas vêzes mais complicados, a tratar do assunto que, é evidente, não é tão só de natureza lingüística.

(*) E o presente estudo ampliação do que foi publicado com o títuto Conceito do Correto a Incorreto na Linguagem nos Estudos Filológicos - Homenagem a Serafín da Silva Nefo, Rio, 1967, da p. 221 à 229.

(1) P. ex., do Brasil, a Revista de Língua Porfuguêsa - Arquivos de estudos relativas ao idioma - liferatura nacionais incluía no primeiro número, Rio, 1919, à p. 111, . O que é correto de autoria de Cândido Lago, e no n.o 3, 1920, p. 214, era constituída uma secção de consultas, "no pensamento de ser útil aos seus leitores", e, para isto, era incumbido "um dos eminentes colaboradores... para a elucidação das dúvidas".

De Portugal, convém citar Cândido de Figueiredo com as Liçōes Práticas da Língua Portuguêsa, 3 vls., 1890 a 1900, e, mais recente, a Revista de Porfugal - série A - Língua Portuguâsa, que, no prefácio do v. I, p. 5, 1942, assim justificava o seu aparecimento: "Aqui estamos, portanto, para erguer o nosso protesto, para congregar à volta desta revista quantos oueiram contribuir, com fé e-entusiasmo, para apontar à execração dos bons Porfuguêses tudo o que deturpe a linguagem sã, as boas maneiras de dizer e escrever e - alto sentido da cultura vernácula". 
Dedicou-se ao problema, com desenvoltura, Otto Jespersen, em mais de uma obra, principalmente em Humanidad, Nación, Individuo desde el punto de vista lingüístico (2), reservando-lhe dois capítulos: "critérios de correção" e "boa e correta linguagem".

Deu ensejo ao primeiro capítulo uma obra de Adolf Noreen (1892), em que êste defende o critério a que chamou racional ou de senso comum, cuja fórmula se resume: "O melhor é o que pode ser apreendido mais exata e mais ràpidamente pelo ouvinte, e pode ser produzido mais fàcilmente pelo locutor". Outro autor, Flodström, assim a modificou: "O melhor é a forma de falar que reune a maior simplicidade possivel com a necessária inteligibilidade". Anteriormente, o critério fôra assim formulado por E. Tegnér: "O que é expressado mais fàcilmente, é mais fàcilmente compreendido". Tal critério, diz Jespersen, se baseia na utilidade, e por isto the deu o nome de energético, "pois gira em tôrno de uma economia do esfôrço (ou do gasto de energia), tanto da parte do locutor quanto da do ouvinte". Conforme a Setälä (1904), isso não resolve a questão "se uma forma é correta ou incorreta, porém exclusivamente se é prestadia e útil".

E para expor a sua opinião, arrola Jespersen sete critérios que são por êle analisados um por um - o critério de autoridade, o critério geográfico, o literário, o aristocrático, o democrático, o lógico, e o estético - para concluir o capítulo com estas palavras: "Cada um dos critérios examinados tem algo que possui uma significação positiva". E no capítulo seguinte propõe o seu ponto-de-vista, de que salientamos o que nos parece básico, isto é, consoante êle, deve-se ter em conta duas coisas: "Primeiro, a clareza de pensamento, que se refere à compreensão da linguagem, o lado puramente intelectual, e depois a beleza, o prazer estético que pode produzir no ouvinte ou leitor, algo que tem relação com os sentimentos, algo emocional", e conclui propondo "os seguintes estádios":

linguagem $\left\{\begin{array}{l}\text { correta } \\ \text { inteligível } \\ \text { boa }\left\{\begin{array}{l}\text { clara } \\ \text { bela }\end{array}\right.\end{array}\right.$

"Muitas coisas, diz $O$. Jespersen, podem ser inteligíveis e ser enunciadas corretamente e, nada obstante, não ser claras nem belas. Do mesmo modo, uma coisa pode ser clara sem ser, por isso,

(2) Tradução espanhola, Buenos Aires, 1947, de Mankind, Nation, end Individual from a linguistic point of view, Oslo e Cambridge, 1925. V. também F. M. Pettorino, Elementos do Análisis Lingüístico, Valparaiso, 1962, da p. 345 à 378. 
bela e vice-versa", e tratando da clareza e da beleza "penetramos na ciência do Estilo".

O critério de Jespersen tem o defeito dos demais, que não distinguem entre a linguagem falada ou corrente e a linguagem escrita ou especificamente literária.

Examinemos agora, embora perfunctòriamente, aquêles critérios e contra os quais fazemos nossos os principais argumentos de Jespersen, e aqui os critérios são apresentados em outra seqüência e algum tanto modificados:

O critério geográfico decide o correto e o incorreto segundo o padrão da fala de uma cidade ou região. Com êste critério, admitese que há uma fala modêlo, superior, pelo qual todos se devem pautar. Além de não ser prático, êsse critério não é científico. Não é prático, porque obrigaria uma coletividade a sujeitar-se à fala de outra, de que nem sempre se conhece, ou para conhecê-la suficiente, teríamos de recorrer a terceiros. Não é científico, pois que tão bem fala uma coletividade num lugar como nos demais. Esste critério, se fôsse exeqüível, deixaria de lado a linguagem literária, porque se importaria exclusivamente com a modalidade oral.

O critério estético afirma que é correto na linguagem o que satisfaz o nosso sentido artístico ou sentimento estético. Em outras palavras, a linguagem correta vem a ser a "linguagem bela" ou "eufônica".

E verdade que, entre duas expressões, uma seja mais harmoniosa que outra, mas, na realidade, o belo não tem relação alguma com a correção da linguagem, e tanto isto é verdade que uma expressão pode ser eufônica e, no entanto, pode destoar do uso geral ou ser errada sob o critério tradicional ou gramatical.

O critério estético é muito pessoal, pois pode suceder que o belo para um não o seja para outro.

Critério lógico - Este assevera que a correção de uma expressão depende de sua conformidade com as leis universais do pensamento. Pelo contrário, o que está em conflito com o pensamento lógico, é incorreto.

Mas, na verdade, a língua não é expressão do pensamento lógico, porém de tôda atividade espiritual ou psicológica. Há quem afirme que "a linguagem não é lógica nem ilógica, mas alógica". Na realidade, a língua possui a sua própria lógica, que, não obstante, nem sempre concorda com as leis universais do pensamento verdadeiramente lógico. 
Uma expressão correta lingüisticamente não o é lògicamente (3): Dois mais dois são cinco. 0 milho comeu a galinha. O verbo embarcar, apesar de formado na base de barco ou barca, usa-se para qualquer meio de locomoção - embarcar de navio, embarcar de aviāo, etc. Diz-se fazer a barba, quando lògicamente se deveria dizer desfazer a barba. Na piscina só deveria haver peixes, e no aquário só água. Não obstante, nos aquários há peixes, e na piscina se toma banho.

A substância é que tem qualidade e quantidade. Assim, o adjetivo não deveria concordar com o substantivo, nem em número $e$ muito menos em gênero.

Por que as coisas, os atos, as qualidades têm gênero?

O crifério aristocrático baseia-se na linguagem das classes superiores ou na linguagem da boa sociedade. Problemas que surgem: - Que são classes superiores? Que é a boa sociedade? - Qual é a fronteira entre aquelas $e$ as classes inferiores? As classes superiores seriam a côrte e a nobreza nos países monárquicos? Ou os altos funcionários do govêrno? As classes profissionais? As classes cultas, que possuem melhor educação?

$E$, pois, difícil definir que classe superior se há de escolher para modêlo.

Não se nega, todavia, que as distinções de classe têm desempenhado influência na evolução lingüística, e na decisão do que é bom ou mau, e, por outro lado, as classes inferiores, natural ou convencionalmente assim consideradas, em geral se esforçam em imitar os meios cultos. Contudo, nem tudo é digno de imitação. Ademais, não se faz distinção entre o falar e o escrever.

O critério autoritativo ou de autoridade, por sua vez, apresenta outros problemas - Que autoridade serviria para modêlo de linguagem? A autoridade do Ministério da Educação? A autoridade das academias? A autoridade da gramática e do dicionário? Ou a autoridade dos escritores? Aqui, então, entramos num critério afim - o critério literário ou histórico-literário. Baseia-se nos autores ou, melhor, nos clássicos (4). Para isto, teríamos necessidade de avaliar

(3) "Una falsedad filosófica, un absurdo empírico y hasta una inexactitud lógica pueden pre. sentarse en forma idiomáticamente correcta. La justeza o corrección gramatical no tiene nada que ver con la exactisud empírica, ni con la histórica, ni con la lógica. Ni tampoco con la verdad. Nada hay en el reino del error ni en el la mentira que no pueda envolverse en palabras $y$ estilizarse en forma impecable. (K. Vossler Filosofía del Lenguaje, $B$. Aires, 1943, p. 27-28).

(4) "O critério da fidelidade passiva aos chamados textos clássicos parte de um equívoco sô. bre o conceito de uso lingüístico. Não leva em conta a limitaçāo, no tempo e no espaço, dos usos literários, e atribui além disso a escritores ingênuos e despreocupados no dizer, 
todos os literatos, os quais pertencem a épocas diversas e sofreram, portanto, influxos diversos.

A linguagem de um difere da de outro, e mesmo um escritor pode redigir de várias maneiras em diferentes épocas de sua vida. Há autores cujas obras se recomendam apenas pelas suas idéias e não pela linguagem, e outros vice-versa.

O fato de uma expressão ter sido empregada por um autor ou mesmo por um grande clássico não é prova de que é correta gramaticalmente. Afinal, êste critério só poderia servir para a linguagem literária, e a linguagem oral não poderia contar com êle, pois não se tolera que a fala seja igual à escrita.

Para assentar que autores se devem seguir, é preciso, antes de tudo, proceder à valoração literária, mas, por falta de um critério geral, esta valoração é, por si mesma, duvidosa, de modo que as opiniões podem diferir muito.

Há aqui um círculo vicioso: A melhor linguagem é a que se encontra nos melhores escritores, e consideram-se como melhores escritores aquêles que melhor escrevem a língua. Não obstante, os escritores nos ajudam a decidir problemas de correção, mas tão só para a modalidade escrita.

O critério histórico-natural baseia-se na doutrina predominante em certo período do séc. 19, de que a língua é um organismo que se desenvolve muito melhor em estado de completa liberdade, de modo que tôda dogmatização ou intromissão na língua é prejudicial. Assim, neste critério, nada é correto nem incorreto(5).

Este critério faz lembrar a ausência de qualquer regra de civilidade na vida do indivíduo e nas relações com os seus semelhantes.

O critério democrático ou, pràticamente idêntico, o do uso, fundamenta-se na suposição de que qualquèr indivíduo é tão bom quato outro qualquer, e o que se deve ter em conta é o número dos que usam tal ou qual expressão. O uso é, de fato, a suprema autoridade, e o reconhecem pràticamente todos os lingüistas. Ouçamos a alguns: "O uso linguístico, uma vez estabelecido e aceito, nunca erra". (Madvig). "O único critério de correção é o costume e o uso

ccmo eram os chamados clássicos porfuguêses, uma intenção consciente de rigorismo e purismo que não tiveram". (J. Mattoso Câmara Júnior, Boletim de Filologia, dez. 1946, fasc. IV, p. 234).

(5) “La grammaire descriptive, dégagée de toute préoccupation pédagogique, ne se propose que de fournir. des faits au linguiste; pour elle il n'y a pas de fautes, pas de bon ef de mauvais français, mais seulement des aspects multiples de la langue" "(J.' Marouzeau, La Linguistique ou Science du Langage, 3.3 ed., Paris, 1960, D. 53). 
comum da coletividade. Gramaticalmente correto é o que está aceito pelo grande corpo dos que falam o mesmo idioma". (Sayce). "Tudo o que está em uso geral numa língua é, por esta razão, gramaticalmente correto". (Sweet).

Sim, o critério do uso é importantíssimo, basilar, e antiqüíssimo, porém, de outro lado, fundamental é que se faça distinção entre o uso oral e o uso escrito. Os critérios até agora apresentados são falhos porque não fazem essa distinção; são unilaterais - ou salientam o uso oral, ou salientam o uso escrito, ou, o que é mais grave, misturam ambos.

A finalidade da linguagem numa e noutra não é a mesma, e - não distigui-la é continuar na insolubilidade do problema. São de Charles Bally estas palavras: "A razão de ser e as condições de existência da língua escrita são essencialmente diferentes das da língua falada" (6).

A êsse critério, que tem essa distinção como básica, denominamos teleológico ou sociológico, porque atende à finalidade da linguagem, assim como ao meio social em que vivem os indivíduos.

Antes de o expormos, convém referir-se a outro, de que Jespersen não teve conhecimento ou não tomou em consideração. Isso diz respeito ao critério funcional, cujo intérprete e defensor é Henri Frei (7), o qual "faz depender a correção ou a incorreção dos fatos lingüísticos do seu grau de conformidade com uma função dada que têm de suprir". Sob êsse aspecto, o incorreto, afirma êsse A., é "o que não é adequado a uma função dada ( $p$. ex.: clareza, economia, expressividade, etc.)". Toma, sim, em consideração a língua falada e a escrita, mas aquela forma a base do estudo. Reconhece finalidade na linguagem, porém "inconsciente e empírica agindo na obscuridade e às cegas".

Como o próprio Frei declarou, "a lingüística funcional é uma ciência explicativa; ela pretende explicar os fenômenos que cons. tituem o funcionamento da linguagem".

Conclui-se daí que é um critério de explicações. O critério teleológico ou sociológico não se importa com as explicações dos fatos, reconhecidas e subscritas, mas dá ênfase ao âmbito social em que êles se verificam.

Considerando a modalidade oral, convém fazer distinção entre

(6) Le Langage of la Vie, Zurique, 1935, p. 102.

(7) La Grammaire des Fautes - Introduction a la Linguistique Fonctionnelle, Paris, Genebra, Lípsia, 1929, em cuja obra o A. aplicou o métcdo de seu mestre Charles Bally exarado em Le langage ot la Vie. 
linguagem oral em geral e linguagem oral em particular, do meio culto.

Na linguagem oral em geral, incluem-se pessoas incultas e pessoas cultas que falam despreocupadamente.

A linguagem falada é instrumento de intercâmbio humano (8), é um meio de comunicar e de receber idéias e sentimentos, os quais são nossas necessidades ou giram em tôrno de interêsses da vida. Essa comunicação e recepção de idéias e sentimentos é uma troca que exige mútua compreensão, e, para que se alcance êste objetivo, é mister que a fala de um seja a mesma que a de outro (9).

E quanto maior fôr a clareza do locutor, como também quanto maior fôr a potência receptiva do ouvinte, tanto maior será a facilidade das relações sociais. Pode acontecer que a clareza do locutor não o seja para o ouvinte, porquanto não é possível haver uma equação perfeita entre dois espíritos, os quais dependem da índole, inteligência, instrução, educação, sensibilidade, etc. Assim se conclui que existem graus de clareza e de compreensibilidade. Afinal, a conversação é um verdadeiro duelo, e, no embate de idéias e sentimentos, cada qual deve defender ou atacar, conforme se agitam os seus interêsses e necessidades.

Dirão que tal conceito é utilitarista. Não o contradizendo, senão confirmando, nós acrescentaremos que êle emerge da vida, da realidade da vida.

Em conseqüência, as relações sociais são facilitadas, na razão direta, pela clareza da linguagem, e, ao contrário, se dificultam, também na razão direta, pela obscuridade.

Visto como a linguagem obtém sua eficácia na facilidade das relações sociais, o claro é o que é correto, e, inversamente, a linguagem não obtém sua eficácia ou a obtém insuficiente, então temos • obscuro, e o obscuro é o que é incorreto. Em outras palavras: Quanto maior fôr a obscuridade, tanto maior será a incorreção. Dedução: A clareza se identifica com a correção, e a obscuridade com a incorreção.

(8) "L'objet du langage est de faciliter les relations entre les hommes" (A. Meillet, Linguistique Historique et linguistique Gónérale, 1, 2.a ed., Paris, 1926, p. 116).

"La langue, comme toutes les institutions sociales, est un moyen de vivre socialement" (Ch. Bally, O. c., p. 195).

(9) Não tem cabimento, pois, tomar em consideração, p. ex., dois individuos cujas linguas ou dialetos não sejam os mesmos.

"La nécessité même d’être compris impose à tous les sujets le maintien de la plus grande identité possible dans les usages linguistiques" (A. Meillet, O. C., p. 17). "L'usage est toujours détérminé par l'intérêt de la communauté, qui est ici le besoin d'être compris". (J. Vendryès, Le langage, Paris ,1921, p. 283). 
Se há uma penalidade para a obseuridade, como de fato há, é justamente o prejuízo ou embaraço que daí decorre contra os próprios interêsses do falante ou contra os de outrem.

Os casos em que o locutor fala obscuro propositadamente, devem ser considerados como defesa de seus interêsses.

- Quer dizer, então, que o indivíduo pode falar como quer, contanto que satisfaça a clareza?

- Em princípio, sim; o indivíduo pode falar como quer, contanto que satisfaça a clareza, mas convém frisar que isto se verifica no meio inculto, entre os incultos, entre os analfabetos e semianalfabetos, como também entre os alfabetizados ou mesmo cultos que falam despreocupadamente em certos meios (10).

Vejamos agora o correto e o incorreto na linguagem oral entre as pessoas cultas ou no meio culto.

Os indivíduos cultos possuem mais liberdade em falar à vontade que os incultos, mas essa liberdade tem limites: $1 .^{\circ}$ ) a intercompreensão (clareza); $2^{\circ}$ ) a coerção social lingüística.

Se thes apraz falar de qualquer modo, comprometem a clareza. Os ouvintes não os compreendem, e não os compreendendo, o comércio social não se realiza ou se realiza com dificuldades.

Por outro lado, 0 indivíduo sòzinho nada ou quase nada pode fazer perante a coerção social que também se exerce na linguagem. $P$. ex., não pode mudar o gênero dos substantivos; não pode usar indiferentemente uma concordância por outra; não pode empregar indiferentemente um vocábulo por outro; etc. (11).

Destarte, deve-se conformar a linguagem com o meio em que se vive, e no meio em que se vive, deve-se conformar com o máximo número. Do contrário, ficar-se-á isolado, e o isolado é êrro. Se todos dizer - projetil, o chaminé, cidadóes, me diga, etc. - quem disser diferentemente, mesmo que seja claro, mesmo que se espelhe na tradição gramatical, terá cometido êrro por insulamento (12).

(10) "E preciso um esfôrço consciente contínuo para manter-nos dentro do que está normalmente estabelecido".

"A línqua popular, própria das massas mais ou menos iletradas, quase não reage contra o fator individual de mudança desde que essa mudança näo prejudique própriamente a in. teligibilidade". (J. Mattoso Câmara Jr., Manual de Expressio Oral - Eserita, Rio, 1961, p. 112):

(11) "Cette limitation de la liberté tient au besoin d'être compris, c'est-à-dire qu'elle est de même sorte que les autres lois qui régissent notre -vie sociale" (M. Bréal, Essaí de Sémantique, 6.a ed., p. 257). V. ainda em Charles Bally, o. C., o cap. V: Ls contrainte sociale dans le langage.

(12) "Pour qu'une infraction prenne force de loi, il faut. que tous les membres de la communauté soient également disposés à la commetre, c'est-à dire qu'elle soit sentie comme règle ef par suite ne soit plus une infraction" (J. Vendryès, le Langago, Paris, 1921, p. 283). 
E verdade que, em muitos casos, é difícil descobrir o máximo número de uma coletividade, em vista do choque fatal entre a linguagem oral e a modalidade escrita (expressões literárias, técnicas, etc.). A uniformidade absoluta é um mito, não só dentro de uma coletividade, mas também considerada no próprio indivíduo, visto que a linguagem depende de circunstâncias internas e externas.

Muitas dessas variabilidades, em virtude de serem momentâneas ou em vista de dependerem da criação individual (estilo), não deslocam o indivíduo para o insulamento no meio social culto, e, portanto, não está êle sujeito a sanção.

- Qual sanção?

- Quem se isola, fica sendo forçosamente objeto de curiosidade que se resume no ridículo (13).

Não querendo o indivíduo ser ridicularizado, há de conformar - seu falar com o ambiente social em que vive (14). Mas, no meio culto, além do desvio pròpriamente lingüístico, há a considerar os lados ético e estético, os quais não podem, nem devem ser desprezados, uma vez que integram a vida como ela é. Qualquer infra-

(13) "Quand une infraction se produit de la part d'un individu isolé, elle est immédiatement reprise; le ridicule punit assez le coupable pour lui óter l'envie de recommencer" (id.". ibidem, p. 283).

"Dans la bonne société, le ridicule est une sanction plus cruelle que le fouet pour l'esclave ou pour l'écolier le bonnet d'âne" (Charles Bally, o.c., p. 188). "Surtout chez l'homme cultivée, la faute peut apparaître comme un délit punissable en soi, une injure faite à la langue" (Id., ib., p. 194).

"Le ridicule est la sonction immédiate de toutes les. déviations individuelles" (A. Meillet, o. c., p. 17).

"Ognuno, se vuole essere compreso, deve curare, pena il ridicolo, la maggiore conformità possibile della sua lingua all'uso-collettivo, ..." (A. Pagliaro, Sommario di Linguistica Arioeuropea, I, Roma, 1930, p. 88).

"La parola o le parole pronunziate al nuovo modo sono, rispetto alla norma costituita dalle relative isoglosse nelia comunita linguistica cui appartiene l'individuo innovante, un "errore" o meglio una sing̣olarità; sinģolarità chè può provocare la mancanza di com. prensione da parte di chi ascolta, o richiamare lo scherno o anche solo la meraviglia" (V. Pisani, L'Etimologia, Milão, 1947, p. 95).

"Estas formas são ainda consideradas incorretas, mesmo por aquêles que as empregam, a pento de se sentirem envergonhados ou perplexos quando sāo apanhados em flagrante "delito" de lesa-gramática" (Paivo Boléo, Língua Falada, Lógica e Clássicos, Coimbra, 1935, p. 10).

(14) "In our community, afirma L. Bloomfield, with its tradition about the "correctness" of speech-forms, the speaker asks "Which form is better?" instead of asking "With wich persons shall I apree in speech?" (Langage, Londres, 1955, p. 477).

"Convém, .... também uma adaptação às preferências do nosso ambiente social costu. meiro, pois o uso divergente pode determinar uma estranheza que é sempre danosa para a espontaneidade da compreensōo lingülstica. (J. Mattoso Câmara Jr., Manual de Expressão Oral e Escrita, Rio, 1961, p. 117).

"Adherence to the rules becomes one symbol of class membership". "The acquisition of "correct" habits of speech and writing becomes one of the rungs in the ladder of social sucess". (Ch. F. Hockett, A Courso in Modern Linguistics, N. lorque, 1965, p. 471-472). 
ção dêles acarreta igualmente o ridículo dos ouvintes ou conviventes, e cuja intensidade emocional depende da maior ou menor educação dêstes.

Há desvio ético quando, fora do seu meio, se emprega gíria ou expressões chulas.

Há desvio estético quando, no meio culto, se usa o patoá, isto é, a linguagem do caipira. Trata-se de fala de meio social inferior, naturalmente ou convencionalmente.

Há ainda desvio estético quando se empregam expressões peculiares à linguagem literária.

O desvio será isoglótico ou geográfico, se o indivíduo vier a usar dialetismos ou a modalidade lingüística de outra região. $E$, por fim, o desvio será cronológico ou histórico, se empregar expressões arcaicas, que não vigoram na atualidade no meio em que vive.

Não deixam o indivíduo isolado as variações da reversibilidade que se podem assim concretizar: longe - longi; forte - forti - forhte; andar - andá - andarh; mássimo - mácsimo; interêsse - interésse; loiro - louro; registro - registo; casão - casona - casarão; diga-me - me diga; comecei a fazer - comecei de fazer; etc. São variantes em sentido amplo.

Nem todos os desvios da linguagem oral devem estar sujeitos ao mesmo critério de julgamento, mas, por outro lado, não se poderia apresentar um quadro sistemático, senão aproximativamente, daqueles que mais chamam a atenção e que, portanto, devem ser evitados: $\left.1 .^{\circ}\right)$ deslocação da tônica: cáfe, lirío; $2^{\circ}$ ) timbre de certas vogais tônicas: cafê, óvo; $3^{\circ}{ }^{\circ}$ ) troca de vogais: quefé, uvo (ôvo ou uva;; $\left.4 .^{\circ}\right)$ troca de consoantes: binho, herrói, azúcar; $5 .^{\circ}$ ) ensurdecimento não final: sbrado (sobrado), croa (coroa); $6 .^{\circ}$ ) ensurdecimento do s do plural nos substantivos e adjetivos: os livro, as mão, as noz amarga, etc.; $7 .^{\circ}$ ) emprêgo de uma desinência por outra: eu trabalha, nós fala, os pãos, etc.; $8 .^{\circ}$ ) discordâncias: os homens fugiv; 0 diretor e o secretário saiv; fruta gostoso, frutas gostosa; $9 . .^{\circ}$ ) falha de regência: gosto frutas, etc.

São indiferentes aos indivíduos os fenômenos lingüísticos do passado e os de outro ou outros meios sociais e geográficos. Só o uso atual e seu meio social-geográfico lhes satisfazem as necessidades da comunicação e compreensibilidade.

A atualidade e o uso local são, pois, as únicas realidades em que se deve considerar o máximo número. Defende-se, assim, também o regionalismo. 
Assim, o correto é o que, além de claro, está de conformidade com o meio social-geográfico culto da atualidade, e o incorreto é o contrário - o obscuro, o desvio ou o insulamento dentro dêsse meio na atualidade.

Se, às vêzes, é impossível conhecer o máximo número, é recomendável, então, conformar-se com a fala de outrem, com quem se está em contacto. É verdade que o desvio individual do meio geofísico é o ponto de partida da evolução lingüística. Isto quer dizer que haverá um momento mais ou menos prolongado em que se manifesta uma luta entre o tradicional e a inovação. E assim como num determinado ponto do meio geofísico se revelou a novidade, coincidentemente o mesmo fenômeno se manifesta em outro ou outros meios, além de se propagar por imitação. E destarte se formará o nôvo máximo número e há renovação do meio lingüístico.

Até aqui o conceito do correto e incorreto na linguagem oral. Agora, vejamo-lo na linguagem escrita, ou melhor, literária. Linguagem literária ou língua literária é a modalidade lingüística escrita, empregada artisticamente pelos literatos. $E$, em regra, conservadora, tradicional, e, por isto, arcaica; o que se deve principalmente à dependência da escrita.

A linguagem literária não tem a mesma finalidade que a modalidade oral. Segundo Charles Bally, a sua finalidade é a satisfação estética da própria linguagem. É concepção da linguagem pela linguagem - ars gratia artis. Na realidade, nesse instrumento indireto de intercâmbio humano, há, senão pròpriamente a subordinação do útil (interêsses, necessidades) ao estético, pelo menos uma equiparação de ambos.

Há uma grande diferença entre a modalidade oral e a escrita ou, especificadamente, literária.

Enquanto na língua falada predomina o lado social ou da coletividade sôbre o individual, na linguagem literária há o predominio, em regra, do individual sôbre o social. Por isto a linguagem literária é essencialmente pessoal, afetiva e estética.

Ignorando em que mãos vão parar os seus escritos, e, portanto, desconhecendo a capacidade intelectiva dos leitores, pouco se dá ao escritor a clareza, que, então, é bem relativa.

Sendo a modalidade lingüística literária essencialmente pessoal, afetiva e estética, compreende-se que haja escritores liberais que freqüente ou sistemàticamente rompem com a tradição gramatical escrita. Sobrepõem à gramática a estilística. Mesmo assim há limite, porquanto numa obra pode-se romper com as normas gramati- 
cais, porém nunca se pode romper com o sistema, porque êste é basilar, é estrutural.

Diz Eugênio Coseriu que o sistema pode ser comparado à tela e às côres de um pintor: "O pintor não pode sair da tela e não pode empregar côres que não tem, mos, dentro dos limites da tela e no emprêgo das côres que possui, sua liberdade expressiva é absoluta". O sistema lingüístico proporciona "os meios para sua expressão inédita, porém ao mesmo tempo compreensível para os que utilizam o mesmo sistema" (15).

Isto quer dizer, p. ex., que um escritor pode ir contra a norma, apresentando um plural cidadöes ou cidadães, com terminações existentes no sistema, mas não pode empregar terminação diferente, inexistente nesse sistema, p. ex., cidadãoxen ou cidadãoetá, etc., e isto em todos os vocábulos terminados em -ão.

Não só se fará incompreendido, como também cairá no ridículo, além de deformar estruturalmente a língua de que se serve, apresentando um escrito que se poderia bem qualificar como obra de mentecapto. Assim, dada a absoluta liberdade do autor perante as normas, não se podem classificar êsses desvios como erros, mas como manifestações estilísticas, estéticas e emotivas - tôdas corretas - a demonstrar a personalidade do escritor (16). Em vista do quê, os exemplos dos escritores ou a autoridade dos escritores não podem servir de critério da correção para a linguagem oral, mas podem sê-lo perfeitamente para a própria modalidade literária.

Vamos agora concluir com ilustrações práticas:

1.ค) Na linguagem oral do meio inculto e mesmo de cultos que falem despreocupadamente, respeitadas certas conveniências referentes a pessoa, tempo e lugar, a clareza é a suprema lei.

A propósito, é sabido que, entre os caipiras, entre os índios, entre os povos selvagens de qualquer parte do mundo, não há nem houve, nem haverá pròpriamente o problema lingüístico do correto e do incorreto, segundo a nossa concepção tradicional,

(15) Sistema, Norma y Habla, Montevidéu, 1952, p. 58.

(16) "Estranho como pareça, é perfeitamente lícito afirmar que uma atitude de independência em face de regras gramaticais cube de direjto aos literatos, antes que aos que usam a língua com objetivos prátices. Ds literato espera-se uma visāo pessoal em questōes de forma linguística, iá que a língua é a sua preocupaçăo primária e a matéria-prima de sua arte". (J. Mattoso Câmara Jr.; Manual de Expressão Oral e Escrita, Rio, 1961, p. 12). V. ainda A. Pagliaro, Sommario di Linguistica Arioeuropea, 1, Rcma, 1930, p. 152, nota 4. Sāo da Charles Bailly estas palavras: "Beaucoup de fautes de langue répondent aux nécessités de la logique grammaticale; d'autres, .... aux exigences de l'expression émotive" (Le Langrge el la Vie, Zuriaue, 1935, D. 42). 
mas houve, há ou haverá o problema lingüístico da clareza e da obscuridade. $E$ verdade que pode haver, entre êsses analfabetos, problema lingüístico de caráter nacionalista, se assim me posso exprimir.

Quando, há anos, em trabalho de campo, eu pesquisava a língua dos índios caingangues, de Palmas, neste Estado, ao registrar o vocábulo xapé, que quer dizer "chapéu", lembrei ao meu "professor" a existência de kritá ou krintaire pertencente a outra tribo, da mesma língua. $O$ índio prontamente me respondeu que kritá ou krintaire não é usado entre êles e sim entre os xocréns, de Santa Catarina, com os quais não se dão, e por isto fazem questão de não empregar seus modismos. Preferem xapé que, na verdade, é uma adaptação do port. chapéu. De certo modo se enquadra na clareza-obscuridade, visto que, usada a expressão estranha, de outro falar, poderia causar incompreensão.

2. ) Na linguagem oral do meio culto, pode a clareza não ter primazia, mas deve tê-la a correção gramatical em sentido bem amplo.

Ao sentar-se alguém à mesa para a refeição, pode ficar debruçado. Pode comer com as mãos. Pode mastigar com a bôca aberta. Pode, diante de visita, espreguiçar-se a valer. E a série a que chamamos atos de incivilidade, poderia ser aumentada; é evidente.

Assim como há leis das boas-maneiras, observadas no trato social, assim há leis da boa linguagem, que devem ser observadas, respeitadas pelas pessoas de cultura.

E como as boas-maneiras são cultivadas, assim também a boa linguagem deve ser cultivada. Evite-se, contudo, a afetação; devemos ser naturais.

A linguagem das pessoas cultas deve ser aproximada da linguagem literária, porém sòbriamente, para evitar ridículos.

Não devemos empregar vocábulos peculiares a esta: olor, odor, atinente $a$, respeitante $a$, consumar, gládio, mancebo, subseqüência, neqüícia, proteiforme, esplender, cessar, róseo, envaidar, etc.; nem giros sintáticos símiles a êstes: fatos são êstes os quais, deu-se-lhe isto, procuremo-la, contaram-mo, contaram-lho, o de que é mister, chegados que foram, etc.;

E lógico que, na conversação, p. ex., entre profissionais, podem e devem ser empregados os têrmos técnicos referentes ao assunto. Nisto não há pedantismo, mas fora daí, sim, há pedantismo, presunção e pode produzir até incompreensão. 
3.9) Por fim, na linguagem literária, a gramática tradicional se subordina à estilística; donde só se pode conceituar o correto e o incorreto pelo prisma do escritor.

E o incorreto passa, então, a "êrro de estilística", isto é, quando uma expressão, apresentada para causar certa impressão ou emoção, não logra êste efeito. 